\title{
PRINCÍPIOS DO PROCESSO ADMINISTRATIVO FEDERAL E A FORMALIDADE DOS ATOS PROCESSUAIS: UMA DISCUSSÃO COM FOCO NO DESENVOLVIMENTO
}

\author{
PRINCIPLES OF FEDERAL ADMINISTRATIVE PROCEDURE AND \\ FORMALITIES ACTS PROCEDURE: A DISCUSSION WITH FOCUS ON \\ DEVELOPMENT
}

\author{
Camila Capucho Cury-Mendes ${ }^{1}$
}

\section{RESUMO}

As boas práticas da Administração Pública estão ligadas aos direitos dos administrados, sendo que a doutrina especializada se preocupa em desenvolver estudos científicos que traduzam a importância da obediência a normas e princípios norteadores do Direito Administrativo. Objetivando verificar o trâmite processual em uma instituição pública, elencou-se os princípios administrativos intimamente relacionados a tais boas práticas administrativas. Realizou-se uma revisão bibliográfica acerca do tema, abordando os princípios da: legalidade, da finalidade, da motivação, da ampla defesa e do contraditório, da razoável duração do processo e da formalidade. Ao final da revisão bibliográfica, e confrontando a rotina diária de uma instituição pública federal, concluiu-se que a observância e a obediência a tais princípios, elencados como os mais relevantes para a prática administrativa, evita a crescente anulação dos processos administrativos que tramitam nas instituições públicas. Deste modo, perseguese a garantia de uma boa gestão pública para os administrados, contribuindo para o desenvolvimento institucional da administração pública brasileira, a qual deve refletir confiabilidade aos seus administrados.

Palavras-chave: Administração Pública, Princípios Administrativos, Formalidade dos Atos Processuais.

\begin{abstract}
Good practices of public administration are linked to the rights of citizens, and the specialized doctrine is concerned to develop scientific studies that reflect the importance of obedience to guiding rules and principles of administrative law. To ascertain the procedural action in a public institution, is listed out-administrative principles closely related to such good administrative practices. We conducted a literature review on the subject, addressing the principles of: legality, purpose, motivation, legal defense and contradictory, of reasonable duration of the process and the formalities. At the end of the literature review, and confronting the daily routine of a federal public institution, it was concluded that the
\end{abstract}

\footnotetext{
${ }^{1}$ Universidade Tecnológica Federal do Paraná. Av. Sete de Setembro, 3165 - Rebouças CEP 80230-901 Curitiba - PR - Brasil. Telefone Geral +55 (41) 3310-4545. Advogada especialista em Direito Administrativo, servidora pública federal. E-mail: c.capucho@hotmail.com
} 
observance and obedience to these principles, listed as the most relevant for administrative practice, prevents the growing annulment of the administrative proceedings before the public institutions. Thus, pursues to guarantee good governance for the administration, contributing to the institutional development of the Brazilian government, which should reflect reliability to its administration.

Keywords: Public Administration, Administrative Principles Formality of Acts Procedure.

\section{Introdução}

A Administração Pública Brasileira presta os seus serviços de forma direta ou indiretamente, por meio de entidades criadas para tal fim. Sendo de uma ou de outra forma, sempre estará presente a preocupação com a qualidade de sua atuação, buscando sobremaneira o atendimento das necessidades da coletividade.

Tanto é assim que estudiosos do ramo buscam demonstrar a importância da observância e da obediência a leis e princípios administrativos, para a prática dos atos processuais administrativos e para o desenvolvimento de sua rotina administrativa.

A busca da satisfação das necessidades da coletividade é o objetivo em toda a Administração Pública. Particularmente, o Direito Administrativo não é um ramo do direito que possui codificação; desta forma, a doutrina administrativista salienta a importância de se observar não apenas a lei, balizador maior da atuação do administrador público, mas também os princípios que regem este ramo do direito público.

Ao observar as boas práticas para a elaboração e o desenvolvimento dos atos processuais, a Administração Pública resguarda-se no sentido de evitar questionamentos e possíveis anulações de procedimentos formais realizados, primando pela qualidade e pela satisfação do interesse púbico.

A não observação de normas legais expressas e de princípios administrativos compromete a qualidade do trâmite processual, podendo acarretar, em algumas situações em que não é possível a convalidação, a anulação sumária de todo o processo.

Assim sendo, diante de uma anulação de um processo em trâmite na administração pública, haverá, inevitavelmente, gasto desnecessário de tempo, de recursos materiais envolvidos e de trabalho dos servidores públicos.

Do exposto, faz-se necessário um estudo sobre o tema, a fim de sejam elencados os princípios administrativos norteadores da atuação de servidores públicos, com foco no desenvolvimento da prática diária das instituições públicas. 
A busca pela qualidade na prática diária da administração pública reflete não apenas a boa gestão dos administradores públicos, mas, acima de tudo, a garantia aos administrados do respeitoaos seus direitos.

Por meio deste estudo, as instituições públicas e a própria instituição em que a pesquisa foi desenvolvida poderão perseguir o fim legal previsto para a administração pública brasileira: o respeito aos princípios norteadores do ramo do direito público e o respeito ao administrado, o qual busca a administração pública para o atendimento das suas necessidades inadiáveis.

\section{Metodologia}

Para o desenvolvimento deste trabalho, realizou-se uma pesquisa do tipo qualitativa, em que foram verificadas situações recorrentes da prática diária da Procuradoria Jurídica junto à Universidade Tecnológica Federal do Paraná.

Foram analisados autos de processos administrativos dos mais variados assuntos, envolvendo licitações e contratos, editais de concursos públicos, minutas de contratos e convênios e processos administrativos, como sindicâncias e processos administrativos disciplinares, processos relacionados a servidores públicos, durante os meses de janeiro de 2014 a outubro de 2015.

Buscou-se verificar, nos autos dos processos, se o servidor público responsável pelo impulso oficial observou os requisitos formais para a condução do trâmite processual, e também se o agente público respeitou os princípios administrativos que balizam a atuação administrativa.

Ademais, esta pesquisa qualitativa teve também como objetivo maior a verificação, dentro dos autos do processo, daqueles princípios administrativos que, se não observados, pudessem conduzir à anulação de um processo em trâmite.

\section{Referencial teórico}

\subsection{A estrutura administrativa brasileira}

A estrutura administrativa brasileira é encontrada na administração direta e indireta dos Poderes Executivo, Legislativo e Judiciário. Entretanto, é o Poder Executivo a administração pública por excelência. 
Di Pietro (2014) conceitua Administração Pública por meio de dois sentidos: o Subjetivo, Formal ou Orgânico, que significa a designação dos entes que exercem a atividade administrativa, as pessoas jurídicas, órgãos e agentes públicos incumbidos de exercer a função pública. O sentido Objetivo, Material ou Funcionaldesigna a natureza da atividade administrativa que os agentes públicos exercem em sua prática diária (DI PIETRO, 2014).

A fim de melhor atender aos seus administrados, a Administração Pública pode vir a prestar serviços públicos de forma direta ou indireta.

Por forma direta vale dizer que é a própria administração quem presta os serviços públicos, sem a intermediação de entidades criadas para tal fim, sendo que "o Estado pode desenvolver por si mesmo as atividades administrativas que tem constitucionalmente a seu encargo". Desta forma, o Estado desempenha as suas atividades ele próprio, centralizando, assim, a prestação de serviços públicos (MELLO, 2014).

Por outro lado, se o Estado presta tais atividades administrativas através de outras entidades, Celso Antônio Bandeira de Mello afirma que há transferência para demais particulares do "exercício de certas atividades que lhe são próprias ou, então, (o Estado) cria outras pessoas, como entidades concebidas para desempenhar cometimentos de sua alçada”. Assim, estaria conceituada a Administração Pública Indireta (MELLO, 2014).

\subsection{A prática administrativa brasileira: atos administrativos e princípios da administração pública}

Tanto na Administração Pública Direta quanto na Indireta, a prática administrativa das instituições públicas está regulamentada por diversos diplomas normativos, como Constituições Federal e Estaduais, Leis, Decretos e Regulamentos, e também por Princípios, considerados pilares de sustentação de todo o ordenamento jurídico brasileiro.

Para a atuação concreta da prática administrativa, os servidores públicos praticam atos administrativos, para o atendimento das necessidades da coletividade. Segundo Celso Antônio Bandeira de Mello, eles são considerados como uma declaração do Estado, no exercício das prerrogativas públicas, almejando um fim público, de interesse da coletividade (MELLO, 2014).

Hely Lopes Meirelles os conceitua paralelamente a Atos Jurídicos, sendo estes "todo aquele que tenha por fim imediato adquirir, resguardar, transferir, modificar ou extinguir direitos". Assim, haveria uma aceitação, imposta, de atos emanados do poder judiciário, por 
parte do cidadão. Assim, aos Atos Administrativos o nobre doutrinador acrescenta a finalidade pública, que, segundo ele, "é própria da espécie e distinta do gênero ato jurídico" (MEIRELLES, 2014).

Entretanto, para que estes atos sejam válidos, perfeitos e eficazes, é imprescindível a observância de algumas normas legais e princípios, explícitos ou implicitamente encontrados nos diversos diplomas normativos.

Segundo a doutrina especializada, dos Princípios de Direito Público se originam os Princípios de Direito Administrativo, sendo específicos para tal ramo do direito, orientando e fundamentando a Formalidade dos Atos Processuais.

A legislação infraconstitucional é clara ao prever, expressamente, os princípios que orientam o trâmite de um Processo Administrativo, em seu aspecto formal. Assim, a Formalidade dos Atos Processuais é condição imprescindível para o desenvolvimento dos procedimentos formais administrativos, sustentada pela Lei de Processo Administrativo Federal no 9.784, de 29 de janeiro de 1999.

A problemática proposta para o presente estudo baseia-se no sentido de que a observância dos Princípios Administrativos, no que se refere à Formalidade dos Atos Processuais, pode garantir o bom desenvolvimento dos procedimentos formais da Administração Pública. Com isso, busca-se evitar o crescente questionamento, por parte do Poder Judiciário, e também pela própria administração pública, de processos administrativos que possam estar maculados por vícios insanáveis de irregularidades, levando à anulação dos mesmos.

\subsection{Objetivo do estudo dos princípios administrativos, em consonância com a rotina da administração pública brasileira}

Pretende-se neste artigo expor os Princípios Administrativos mais relevantes para a prática administrativa, os quais, se ausentes, possam vir a invalidar os processos administrativos das instituições públicas. Uma possível inobservância de tais princípios pode vir a afetar a integridade formal dos atos praticados pela administração pública brasileira.

A importância da identificação de tais princípios pode contribuir para os administradores públicos orientar a sua equipe de trabalho, a fim de evitar anulações dos processos administrativos, que tramitam nas repartições públicas. 
Desta forma, busca-se alcançar a meta de contextualizar a prática administrativa de um modo geral, naquilo que se refere à Formalidade dos Atos Processuais. O bom desenvolvimento da prática administrativa busca alcançar o melhor desempenho da Administração Pública, em especial às boas práticas dos Atos Processuais.

A identificação dos Princípios Administrativospermite ao Administrador Público verificar se a prática administrativa está sendo bem desenvolvida por sua equipe de trabalho. Desta forma, o Administrador Público poderá orientar a sua equipe, a fim de se buscar a máxima eficiência para o serviço público.

\subsection{A observância aos princípios administrativos que balizam a atuação dos gestores públicos}

Segundo Maria Sylvia Zanella Di Pietro, o Direito Administrativo "está informado por determinados princípios, alguns deles próprios também de outros ramos do direito público e outros deles específicos e enquadrados como setoriais". Ademais, por ter o Direito Administrativo origem não codificada, os princípios "sempre representaram papel relevante (...), permitindo à Administração Pública e ao Judiciário estabelecer o necessário equilíbrio entre os direitos dos administrados e as prerrogativas da Administração" (DI PIETRO, 2014).

Princípios, no entendimento de José dos Santos Carvalho Filho, "encerram um conteúdo informador e formador de várias normas". Eles constroem não apenas os preceitos a serem observados pela Administração Pública, mas também os norteadores que contribuirão para o atendimento ao fim público desejado (COSTA, 2005).

Assim, os princípios consistem em sustentáculos do ramo, que se encontram espalhados por todo o ordenamento jurídico brasileiro, podendo ou não estar escritos. Eles são de observância obrigatória no âmbito da Administração Pública Brasileira, sendo considerados pilares para o entendimento e a interpretação de diversos ramos do Direito, em especial do Direito Público como um todo.

$\mathrm{Na}$ visão de José Armando da Costa, princípios são mais importantes do que as normas escritas. Assim, seria "correto dizer que se afronta muito mais o direito quando se desacata um dos seus princípios do que quando se desatende a uma de suas normas textuais" (COSTA, 2005).

No que se refere à utilização dos princípios na prática administrativa, José dos Santos Carvalho Filho afirma que "os princípios (...) são os postulados de maior nível e, portanto, 
obrigam a todos os que se situem nas condições fático-jurídicas a eles inerentes" (CARVALHO FILHO, 2013).

Na opinião de Luan Bertin Mazieri (2015), o meio de busca dos direitos materiais, que é o processo, é permeado por princípios que devem ser buscados pelas partes. Estes valores processuais não apenas diminui o caráter efetivo das formalidades, mas também evita as injustiças frequentemente presentes e de caráter protelatório.

De todos os princípios observados no ramo do Direito Administrativo, podem-se citar aqueles que possuem maior relevância para a prática administrativa, como o Princípio da legalidade, da finalidade, da motivação, da ampla defesa e do contraditório, da razoável duração do processo e da formalidade dos atos processuais.

Segundo Cunha Júnior, “o princípio da legalidade é uma exigência que decorre do Estado de Direito, ou seja, da submissão do Estado ao império da ordem jurídica. A norma deve respaldar o agir e o não agir dos indivíduos" (CUNHA JÚNIOR, 2007).

Para Hely Lopes Meirelles, na administração pública não existe autonomia de vontade. $\mathrm{O}$ administrador deve fazer aquilo que está previsto em lei, sem exercer a sua vontade pessoal. A lei, para os agentes públicos, vai mostrar qual e como deve ser o caminho a percorrer (MEIRELLES, 2014).

Para Carmela Mottecy de Oliveira (1999), é de bom conselho que os atos processuais sejam produzidos observando-se os preceitos legais. Ademais, a consequência lógica da inobservância legal é a inaptidão para que tal ato possa produzir os seus efeitos.

Na visão de Diógenes Gasparini, no que se refere a processo administrativo,este princípio determina que a instauração do procedimento apuratóriose dê com base e para preservar a lei, e deve ser observado em todo o decorrer do processo (GASPARINI, 2008).

Processo, nas palavras de Wagner José Elias Carmo (2014), significa o instrumento que o Estado utiliza para o exercício de seu poder. Resulta, inclusive, em dizer que o processo deve fazer-se presente em todas as atividades do Estado, seja administrativa, legislativa ou jurídica.

No que se refere ao princípio da finalidade, ele reflete a prática um ato administrativo visando ao fim público a que se destina. Juntamente com o princípio do interesse público, busca alcançar os interesses da coletividade, naquilo que se refere às suas necessidades.

Di Pietro leciona que o princípio da finalidade está inserido dentro do princípio da impessoalidade. Na ótica do atendimento aos administrados, a finalidade pública está 
relacionada com a proibição de prejudicar a coletividade ou de favorecer determinados indivíduos, em detrimento do todo, ou de todos (DI PIETRO, 2014).

Para Quintino Lopes Castro Tavares (2010), o interesse público justifica os atos da Administração Pública, conferindo-lhe prerrogativas de presunção a seu favor.

Com base nos estudos de Augusto Tanger Jardim (2003), quando houver violação de preceitos legais e estes vierem a ferir o interesse público, a nulidade constatada nos autos do processo será absoluta. Principalmente em se tratando de processos que tramitam perante a administração pública, estas nulidades, sendo absolutas, poderão vir a anular os processos em trâmite, se impossível for a sua convalidação.

A despeito da exigência legal para a observância da forma para a realização de atos, processuais, Gisele Leite e Denise Heuseler (2009) afirmam que, apesar do progressivo abandono do formalismo por todos defendido, não há ato sem forma, pois é esta que o introduz no processo.

Como uma espécie de confirmação do interesse público, o princípio da motivação dos atos administrativos tem sede legal e se refere à justificativa para a prática de um determinado ato. A sua observância contribui para a transparência administrativa, no que se refere à publicidade dos atos processuais. Assim, deve a Administração, segundo Maria Sylvia Zanella Di Pietro, "indicar os fundamentos de fato e de direito de suas decisões" (DI PIETRO, 2014).

No caso em que os atos administrativos possam vir a afetar direitos e deveres dos administrados, é dever de a Administração Pública permitir o direito à ampla defesa e ao contraditório. Assim, é dado ao investigado o direito de se defender e se manifestar sobre aquilo que a Administração afirma, mediante a utilização de todos os meios de defesa previstos em lei e aceitos pelo Direito. Afirma José Antônio Carvalho Filho que no Estado de Direito não é possível abrir mão do princípio do contraditório e da ampla defesa (CARVALHO FILHO, 2013).

Hely Lopes Meirelles, apud Ada Pellegrini Grinover, afirma que os princípios da ampla defesa e do contraditório são devidos não apenas aos litigantes que se encontrem em situação de litígio, mas a todos aqueles que estão pleiteando algum direito perante a administração pública (MEIRELLES, 2014).

Com relação àrazoável duração do processo, tal princípio traduz a ideia de que a Administração Pública deverá praticar os atos processuais em um espaço de tempo razoável, 
observando o rito processual previsto em lei. Desta forma, para Marçal Justen Filho, “qualquer argumento para justificar a lentidão de um processo administrativo, versando sobre pleito favorável ao particular, esvai-se quando se comprova que, concomitantemente, outros processos recebem tratamento distinto" (JUSTEN FILHO, 2014).

Medauarafirma que, apesar de se estabelecer ritos e prazos para o desenvolvimento dos atos dos processos, a vigência deste princípio "não implica sacrifício do contraditório, ampla defesa, devido processo legal, pautando-se pela proporcionalidade e a conciliação de todos" (MEDAUAR, 2013).

Por formalidade dos atos processuais entende-se um conjunto de boas práticas de atos, que levam a um resultado pretendido. A observância de tais preceitos contribui para a produção de atos válidos, perfeitos e eficazes, e evita a retirada de atos viciados por ilegalidade.

Luan Bertin Mazieri (2015) afirma que como meio de organização para as determinadas lides existentes e para uma resolução dos conflitos no âmbito da sociedade, fez necessário, desde os primórdios da história, a instituição das formalidades do processo.

Maria Sylvia Zanella Di Pietro ensina que o desrespeito às formalidades dos atos processuais, desde que previstas legalmente, determinam a invalidade do ato (DI PIETRO, 2014).

Ainda naquilo que se refere à formalização dos atos, administrativos, Medauar, com ressalvas, discorre acerca do princípio do formalismo moderado. Tal princípio, num primeiro momento, "consiste (...) na previsão de ritos e formas simples, suficientes para propiciar um grau de certeza, segurança, respeito aos direitos dos sujeitos, o contraditório e a ampla defesa". E continua que, ademais, "se traduz na exigência de interpretação flexível e razoável quanto a formas, para evitar que estas sejam vistas como fim em si mesmas, desligadas das verdadeiras finalidades do processo" (MEDAUAR, 2013).

$\mathrm{Na}$ visão de Antonio Carlos Alencar Carvalho (2010), no processo administrativo não se deve imperar a sacralidade das formas, mas sim a instrumentalidade delas, de sorte que os atos processuais produzem efeitos jurídicos regulares se, apesar de não observada certa procedimentalidade, a finalidade a que destinados tenha sido alcançada.

A forma de um ato administrativo é um dos seus elementos de formação. E, segundo Di Pietro, "não só a exteriorização do ato, mas também todas as formalidades devem ser 
observadas durante o processo de formação da vontade da Administração" (DI PIETRO, 2014).

Para Hely Lopes Meirelles, a forma é "o revestimento exteriorizador do ato administrativo". Este elemento "constitui requisito vinculado e imprescindível à sua perfeição" (MEIRELLES, 2014).

Entretanto, Celso Antônio Bandeira de Mello afirma que forma e formalização não devem ser confundidos. A formalização "é um modo específico de apresentação da forma (...), uma dada solenização requerida para o ato". Assim sendo, a formalização é um pressuposto formalístico (MELLO, 2014).

Ainda segundo Celso Antônio Bandeira de Mello, a formalização exige que sejam obedecidas algumas exigências previstas em lei. E o mestre exemplifica que a motivação de um ato é um requisito de importância para a sua formalização (MELLO, 2014).

Não se deve decretar, na visão de Antônio Carlos Alencar Carvalho (2007), em virtude do princípio do formalismo moderado, a nulidade do processo administrativo disciplinar se os atos contaminados de defeitos procedimentais não alteram a valia de outros atos essenciais e desde que o julgamento não tenha sido afetado pelos vícios apontados.

Ressalta-seque existem algumas particularidades da formalização dos atos que podem vir a ser irrelevantes quanto à sua validade. Entretanto, no que se refere à forma de veiculação dos atos administrativos, Celso Antônio Bandeira de Mello afirma que "a função única e específica da formalização prevista (...) é a de apenas uniformizar (...), padronizar o instrumento de veiculação dos distintos atos administrativos" (MELLO, 2014).

Assim, depreende-se que a mera inobservância no quesito de veiculação dos atos não induz invalidade obrigatória, por parte da Administração Pública.

Cintra el al, estudiosos da formalidade dos atos processuais, afirmam que os atos processuais devem ser elaborados segundo os ditames legais, para que seja atingida a sua eficácia. E complementam ao afirmar que "a consequência natural da inobservância da forma estabelecida é que o ato fique privado dos efeitos que ordinariamente haveria de ter" (CINTRA et al. 2014).

Carmela Mottecy de Oliveira (1999) discorre acerca de um outro princípio jurídico, informador do Direito Processual Civil, o princípio da instrumentalidade das formas. Segundo a autora, em virtude de tal princípio da instrumentalidade, os modelos definidos pela lei descrevem não só a forma externa, mas também o que deve conter o ato. 
E acrescentam Gisele Leite e Denise Heuseler (2009) que a instrumentalidade do processo leva aqueles que os praticam a desprezar as formas obsoletas, libertando a extrema pureza e a vitalidade da essência de cada ato.

\section{Resultados e discussão}

O intuito deste estudo é verificar os princípios administrativos mais relevantes para a Administração Pública, e confrontá-los com a formalidade dos atos processuais. Inicialmente, tem-se que o princípio da legalidade é considerado o balizador maior da atuação administrativa brasileira. Por meio dele, o administrador público somente poderá fazer o que está previsto em leis, normas e regulamentos. Assim, deve o agente público observar fielmente os preceitos de orientação para as boas práticas da rotina da administração pública brasileira.

Este princípio levou Hely Lopes Meirelles, 2014, página 90, a afirmar que o administrador público não deve se afastar dele, sob pena de responsabilidade nas esferas disciplinar, civil e criminal.

Do exposto, depreende-se a importância do princípio da legalidade na rotina administrativa das instituições públicas brasileiras, não apenas quanto à invalidade ou anulação do ato administrativo, mas quanto à responsabilidade pessoal do agente público que praticou tal ato.

Ao se colocar o princípio da legalidade em um patamar superior no presente estudo, depreende-se que dele decorrem os demais princípios. Desta forma, tem-se que o princípio da finalidade retira o seu fundamento de validade do princípio da legalidade na medida em que é a lei quem vai definir a finalidade pública para a prática de um dado ato ou conduta.

A finalidade é, ao mesmo tempo, um princípio e um elemento do ato administrativo. Como elemento, a finalidade é um requisito vinculado, ou seja, sua ausência ou a sua indicação incorreta podem gerar anulação do ato administrativo. A sua indicação inadequada pode ensejar a invalidação do ato, por faltar-lhe o elemento essencial em sua formação: o fim público desejado.

Como princípio da administração pública, a finalidade também é conhecida como impessoalidade, ao impor que o agente público observe que o ato seja praticado segundo o fim legal previsto na legislação. Assim, a finalidade denota um sentido de que a administração 
pública sempre vai agir com o objetivo de alcançar o interesse público, como satisfação dos interesses da coletividade.

A ausência da observância do princípio da finalidade acarreta o conhecido “desvio de finalidade", sendo então o ato passível de invalidação.

No que se refere à motivação, cabem inicialmente algumas análises acerca do elemento "motivo" do ato administrativo. Tal elemento possui a característica de ser discricionário, ou seja, o administrador público possui liberdade para agir dentro de uma certa margem de atuação, delimitada pela lei. Assim sendo, o administrador público deve obedecer ao princípio da motivação, ao expor as razões de fato e de direito, que virão a sustentar aquele ato administrativo.

Entretanto, em razão desta margem de liberdade concedida pelo legislador, o administrador público age dentro de um intervalo legal, ficando muitas vezes dificultada a identificação da obediência ao princípio da legalidade. Contudo, a ausência de motivação induz à invalidação do ato administrativo, pois tem-se que a motivação é um requisito relacionado à forma dos atos processuais.

O Estado Democrático de Direito trouxe, para o cidadão, alguns deveres mas, também, algumas prerrogativas frente à administração pública brasileira. Tanto é assim que os Princípios da ampla defesa e do contraditório devem estar presentes em todos os tipos de processos administrativos, tanto os disciplinares quanto os demais.

O princípio da ampla defesa tem sede constitucional e é considerado como uma “cláusula pétrea", por estar previsto no Artigo $5^{\circ}$ da Lei Maior, o qual trata dos direitos e garantias individuais e coletivos.

Este princípio assegura que, diante das manifestações da administração pública, o administrado pode se utilizar de todos os meios de defesa aceitos pelo ordenamento jurídico, desde que moralmente legítimos e não atentatórios à dignidade da pessoa humana.

Desta forma, a ausência de oportunidade de defesa nos processos que tramitam perante a administração pública macula todo o trâmite processual, restando impossibilitada a convalidação, acarretando a anulação do processo.

Em paralelo ao princípio da ampla defesa encontra-se o princípio do contraditório. Este princípio se estende não apenas ao acusado litigante, mas também a todo administrado que se encontre envolvido em algum processo administrativo. 
Este princípio permite ao administrado falar nos autos do processo. Assim, a ele é dada a oportunidade de se manifestar por meio escrito ou mediante de depoimentos e oitivas. Este princípio é um desdobramento do princípio da ampla defesa, e está explicitamente previsto no texto da Constituição Federal de 1988 sendo, assim, considerada uma garantia individual.

Diante da grande relevância destes dois princípios, tem-se que a ausência deles pode vir a acarretar a anulação do processo administrativo, sem a possibilidade de convalidação do mesmo.

No que se refere ao princípio da razoável duração do processo, segundo o que pregam os doutrinadores administrativistas, tem-se que o tempo é um elemento fundamental para a finalização dos procedimentos administrativos.

$\mathrm{O}$ administrado que pleiteia um direito frente à administração pública necessita de garantia de que o seu processo tramitará cronologicamente segundo um prazo razoável para a finalização do mesmo. Assim sendo, a adoção do princípio em tela é uma possibilidade de a administração pública praticar a moralidade administrativa, que tanto contribui para a eficiência da administração pública.

Ademais, este princípio contribui para o cumprimento do prazo necessário ao desenvolvimento dos processos administrativos e também, consequentemente, para a segurança jurídica nas decisões proferidas pelos agentes públicos.

Em se tratando da formalidade dos atos processuais, estase constitui como um princípio que permite a observância de procedimentos formais aos diversos processos que tramitam pelas instituições públicas. A sua exigência se baseiano princípio da legalidade, uma vez que é a lei quem prevê a atuação do agente público, ao praticar um ato administrativo.

A adoção de ritos processuais e formas previstas legalmente traduz a segurança jurídica que os administrados esperam, na busca de seus direitos perante a administração pública.

A busca pela eficiência dos trâmites legais dos processos administrativos levou os estudiosos a desenvolverem o conceito de formalismo moderado, o qual doutrinadores veem com uma certa cautela.

O objetivo do princípio do formalismo moderado é, primordialmente, agilizar o trâmite do rito processual, por meio da adoção de ritos e formas simples. Entretanto, cabe salientar que o objetivo maior do formalismo moderado é abreviar o lapso temporal do trâmite 
processual, sem o afastamento das suas etapas essenciais, como o direito ao contraditório e a ampla defesa. Assim, o desrespeito à formalidade moderada pode acarretar nulidade insanável, levando à anulação do processo.

\section{Considerações finais}

A administração pública brasileira se vale das suas regras e normas para praticar os atos administrativos. Entretanto, por não possuir codificação unitária, os princípios do direito administrativo em muito contribuem para a boa prática administrativa. Aqueles que mais comumente influenciam a rotina administrativa são aqueles que, se desobedecidos, induzem à invalidação dos atos praticados.

A afronta ao princípio da legalidade fere o ordenamento jurídico de forma a tornar inválido por nulidade um ato administrativo. E, a depender da situação, fica impossibilitada a sua convalidação. Com relação ao princípio da finalidade, a não obediência induz a desvio de finalidade, quesito também não passível de convalidação dos atos administrativos. A ausência de motivação, como princípio da administração pública, fere a transparência da administração pública, contribuindo para a ocultação dos fundamentos de fato e de direito, os quais viriam a sustentar a prática de um ato administrativo.

A ausência ou a inadequação do direito à ampla defesa e ao contraditório, em razão de possuírem previsão constitucional, fere as garantias individuais previstas na Carta Maior, levando à anulação dos procedimentos formais da administração pública. Da mesma forma, o princípio da razoável duração do processo não pode ser afastado em detrimento do intuito de se agilizar o trâmite legal previsto para a prática dos atos processuais.

E, por fim, o princípio da formalidade dos atos processuais vem a englobar tudo o que fora exposto anteriormente, no sentido de que para a boa prática dos atos processuais dos agentes públicos, e em respeito à segurança jurídica, deve a administração pública se valer das regras previstas para a elaboração de seus atos administrativos. A desobediência a este princípio formal pode vir a anular todo o trâmite processual praticado, pois a previsão legal para o desenvolvimento de um processo administrativo, no âmbito da administração pública federal, faz lei entre as partes, não apenas para o agente público, mas também para o seu administrado, o qual espera, por parte das instituições, a garantia de seus direitos.

A observância e a obediência a regras explícitas, com o são as leis e as normas, e implícitas, tais como os princípios, contribuem para a implementação da boa gestão das 
instituições públicas. Ademais, garante aos administrados a segurança jurídica nas decisões administrativas.

Desta forma, os atos praticados por servidores públicos estarão respaldados por normas, regras e orientações tais que retiram o seu fundamento de validade dos princípios. Com isso, evita-se desperdício de tempo, material e recursos humanos na elaboração de atos que, posteriormente, possam estar maculados por vícios que os tornariam ilegais ou inconvenientes ou inoportunos.

Em se tratando de Direito Administrativo, a busca da satisfação dos interesses da coletividade é primado maior para a gestão da coisa pública, a qual pertence não ao gestor público, mas à coletividade.

\section{REFERÊNCIAS}

CARMO, Wagner José Elias. Finalidade e natureza do processo . Revista Jus Navigandi, Teresina, ano 19, n. 3849, 14 jan. 2014. Disponível em: <http://jus.com.br/artigos/26387>. Acesso em: 25 nov. 2015.

CARVALHO, Antonio C. A. O princípio do informalismo moderado no processo administrativo disciplinar. Revista Jus Navigandi, Teresina, ano 12, n. 1611, 29 nov. 2007. Disponível em: <http://jus.com.br/artigos/10703>. Acesso em: 25 nov. 2015.

CARVAlHO FILHO, J. S. Processo Administrativo Federal. $5^{\text {a }}$ ed. Revista, Ampliada e Atualizada até 31.03.2013. São Paulo: Atlas, 2013.

CINTRA, A. C. A.; GRINOVER, A. P.; DINAMARCO, C. R. Teoria Geral do Processo. $30^{\mathrm{a}}$ ed. rev. atual. e aum. São Paulo: Malheiros, 2014.

COSTA, J. A. Teoria e Prática do Direito Disciplinar. 5a ed. Brasília: Brasília Jurídica, 2005.

CUNHA JÚNIOR, D. Curso de Direito Administrativo. $6^{\text {a }}$ ed: São Paulo: Editora Podium. 2007.

DI PIETRO, M. S. Z. Direito administrativo. $27^{\mathrm{a}}$ ed. São Paulo: Atlas, 2014.

GASPARINI, D. Direito administrativo. 13 ${ }^{\mathrm{a}}$ ed. Rev. e atual. São Paulo: Saraiva, 2008.

JARDIM, A. T. Das nulidades processuais. Academia Brasileira de Direito Processual Civil. Disponível em: <http://www.abdpc.org.br/abdpc/artigos/augusto\%20tanger\%20jardim\%20formatado.pdf $>$. Acesso em 23 nov 2015.

JUSTEN FILHO, M. Curso de Direito Administrativo. 10 ${ }^{\mathrm{a}}$ ed. atual e ampl. São Paulo: Revista dos Tribunais, 2014. 
LEITE, G, et al. Defeitos dos atos processuais. Revista Âmbito Jurídico. Disponível em: $<$ http://www.ambito-

juridico.com.br/site/index.php?artigo_id=7750\&n_link=revista_artigos_leitura $>$. Acesso em: 23 nov. 2015.

LESSA, S. J. Do processo administrativo disciplinar e da sindicância - doutrina, jurisprudência e prática. $5^{\mathrm{a}}$ ed. Rev e atual. Belo Horizonte: Forum, 2011.

MAZIERI, L. B. Excesso de Formalismo no Processo Civil. Revista Jus Navigandi. Disponível em: <http://jus.com.br/artigos/36394/excesso-de-formalismo-no-processo-civil>. Acesso em 26 nov 2015.

MEDAUAR, O. Direito Administrativo Moderno. $5^{\text {a }}$ edição rev. atual. eampl. São Paulo: Revista dos Tribunais, 2011.

MEIRELLES, H. L. Direito administrativo brasileiro. 24a ed. atual. São Paulo: Malheiros, 1999.

MELLO, C. A. B.Curso de Direito Administrativo. 31ª ed. São Paulo: Malheiros, 2014.

OLIVEIRA, Carmela Mottecy de; OLIVEIRA, Caroline Mottecy de et al. Das nulidades dos atos processuais e seus efeitos. Revista Jus Navigandi, Teresina, ano 4, n. 37, 1 dez. 1999. Disponível em: <http://jus.com.br/artigos/784>. Acesso em: 23 nov. 2015.

TAVARES, Quintino Lopes Castro. Controle da finalidade do ato administrativo.. Revista Jus Navigandi, Teresina, ano 15, n. 2549, 24 jun. $2010 . \quad$ Disponível em: <http://jus.com.br/artigos/15087>. Acesso em: 25 nov. 2015. 